\title{
From biological control to controlling biology
}

\section{BOOK TITLE:}

The Serengeti rules: The quest to discover how life works and why it matters

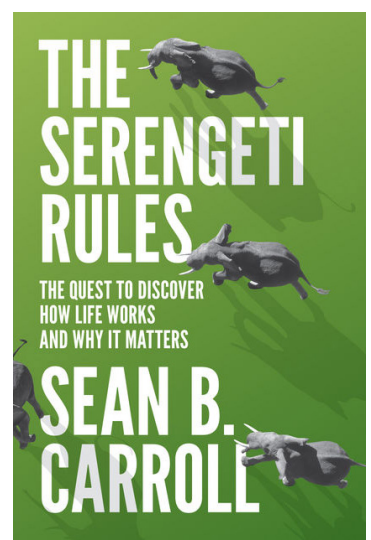

AUTHOR:

Sean B. Carroll

ISBN:

9780691167428 (hardcover)

\section{PUBLISHER:}

Princeton University Press,

Princeton; USD25

\section{PUBLISHED:}

2016

\section{REVIEWER:}

Hannes van Wyk

\section{AFFILIATION:}

Department of Botany and

Zoology, Stellenbosch University,

Stellenbosch, South Africa

\section{EMAIL:}

jhvw@sun.ac.za

\section{HOW TO CITE:}

Van Wyk H. From biological control to controlling biology. S Afr J Sci. 2016;112(11/12), Art. \#a0187, 2 pages. http://dx.doi. org/10.17159/sajs.2016/a0187

(C) 2016. The Author(s). Published under a Creative Commons Attribution Licence.
As an African zoologist, the first part of the title (The Serengeti Rules) did not fascinate me - my first thought was that this book was yet another travel diary of an American tourist about the wonderful African wilderness. However, the subtext (The Quest to Discover How Life Works and Why it Matters) intrigued me, creating an anticipation of understanding life at a deeper level. The author, a scientist, is a gifted writer with a special passion for telling science stories that bridges the space between the worlds of scientists and non-scientists. But the fact that Carroll is a biochemist/molecular biologist, occupying himself with sub-cellular research far removed from life on the Serengeti plains, may create some apprehension. He does not see the understanding and mastery of control systems as a negative but instead views this paradigm shift in the words of Paul Simon - 'These are the days of miracles'. In the Introduction, Carroll lays the foundation for what is to follow: the importance of understanding biological control, i.e. the rules of regulation not only at molecular level but also at ecological level. Carroll poses the question: Why are we humans not applying the same vigour we apply to understanding control at the molecular level to the understanding of rules at higher levels? This is a book about the stories of pioneering scientists who relentlessly worked to understand biological control systems and how this knowledge has helped - and should continue to help - us to manage life on the planet.

Part I of the book, titled 'Everything is regulated', starts with a stand-off between the author and an elephant bull in Tarangire National Park in northern Tanzania. Carroll recaps what happened, the 'fight-or-flight' response, and outlines the research from Harvard physiologist Walter Cannon and his students a century ago when they discovered the 'stress response'. Working on physiological shock related deaths during World War I, Cannon discovered the importance of the buffering capacity of bicarbonate, in 'snatching' several wounded soldiers from death. The 'wisdom of the body', referring to the regulation of vital parameters within a narrow range, intrigued him. He coined the process 'homeostasis', which later became recognised as one of the most fundamental principles in physiology. The 'Cannon story' sets the scene and at the end of Chapter 1, Carroll makes the homeostasis link to numbers regulation in nature and Charles Darwin's remarks about elephant numbers. The next story though is not about Darwin, but about Charles Elton, one of the founders of modern ecology, who was also fascinated by the regulation of animal numbers. From early on, Elton figured out and published on food chains and complex food webs. His fascination with variation in population numbers started when he read about linked fluctuations in species in the food chain. Lemming populations showed these oscillations, and a similar phenomenon was seen in Canadian rabbit populations - called the Lynx relationship. At age 26, Elton wrote his 200-page classic Animal Ecology in just 85 days! In this book, he established several patterns and ecological principles, and emphasised the fundamental importance of regulating animal numbers in a food chain context, with linkage to Cannon's homeostatic control. Carroll skillfully draws a parallel between the contributions to understanding regulation processes in physiology by Cannon and in animal numbers by Elton, thereby converging thoughts towards understanding biological control systems.

In Part II, titled 'The logic of life', Carroll uses a quote from Monod and Jacob: 'Anything that is found to be true of E. coli must be true of elephants'. Carroll reiterates that although ecological and physiological regulation had been established by Elton and Cannon, they were only at the start of untangling the 'rules' of regulation. He proceeds to tell the stories of how the well-known rules of physiological regulation were discovered, specifically through the work of two French biologists, Jacques Monod and Francois Jacob, who described the 'logic' of life. At this point, Carroll reveals the drive and 'logic' behind writing this book about 'analogous rules of regulation and logic' operating not only at the molecular level but also at the ecological level. He convincingly shows that these principles should be taken into account when considering human and environmental health issues, especially when the rules of regulation are broken. Not surprisingly, Chapter 3 forms the foundation of the book, with the Monod and Jacob model surfacing in the chapters to follow. Monod was one of the co-founders of the field of molecular biology and won a Nobel Prize for his role in unravelling the regulation rules at the molecular level using bacteria as model. It was only after Monod discovered a new player in the enzyme regulation game, and managed to 'flip the logic around', that he found that the 'inducer' actually controls a 'repressor', creating a so-called 'double-negative logic'. In order to make progress in understanding how the 'repressor' worked, Monod teamed up with Francois Jacob. Carroll highlights the keystone discovery of negative feedback systems and the importance of Monod and Jacob's discovery of enzyme control reinforcing the generality of these 'rules of regulation'.

In Chapter 4, Carroll continues the historical expedition, telling the reader about the unravelling of the regulation of cholesterol. Carroll describes the courage of scientists, and the importance of serendipity, when telling the tale of the US scientist Ancel Keys. Keys put his own body on the line in a high altitude human experiment to study how the body responds and adjusts to very high altitudes. The high altitude camping got Keys interested in survival diets during the war of 1944, and after the war contrasting statistics regarding deaths from heart disease got his attention. After discovering that poor people generally had lower cholesterol levels in their blood and suffered fewer cardiovascular-related deaths than richer American people, he launched several large-scale studies, including an international study in 1958 with 12000 men on different diets. Keys raised awareness by stating that 'what people were eating was making them sick'. Against this background, Carroll tells the story of heart disease risk and cholesterol regulation and treatment, starting with two adolescent patients of Goldstein who suffered heart attacks at an early age. He explains how US scientists Goldstein and Brown discovered the presence and function of membrane-bound LDL receptors and their absence in patients suffering from hypercholesterolemia. Carroll then asks whether these 'insights into the rules of cholesterol regulation' would ever find their way into treating the disease? Although the answer is yes, it took a rollercoaster ride to get to this point. He tells the story of a Japanese scientist, Akira Endo, who independently worked with fungi and discovered statin therapy, 'a penicillin for cholesterol' - a potent inhibitor of the reductase enzyme Goldstein and Brown identified as an important early 
regulator in the cholesterol control pathway. Although Goldstein and Brown won a Nobel Prize, Endo did not get much recognition (or money) for his discovery and inventions with fungal extracts. In 2003, this oversight was rectified with a conference held in Endo's honour in which Goldstein and Brown acknowledged his contribution to the significant decline in coronary deaths since Ancel Keys raised the warning flag.

The last chapter in Part II, dealing with stories about regulation at cellular level, tells the tale of cancer cells. The title of Chapter 5 - 'Stuck accelerators and broken brakes' - says it all. Carroll introduces the US scientist, Janet Rowley, who made breakthroughs in our understanding of the genetic basis of cancer, starting with leukemia, and described specific chromosomal translocations. From this first evidence for the existence of viral oncogenes, Carroll takes the reader along the path towards the point where it becomes clear that cancer is also a disease of regulation, metaphorically described by Carrol 'like a stuck accelerator in a car' situation. Here the Monod and Jacob model surfaces again, including the possibility of interference with the negative feedback, so 'foot slipping off the (genetic) brake' phenomenon. The next challenge was to find a way to repair the 'genetic brakes' in cancer cells.

To this point in the book, Carroll skillfully introduces the reader to the rules and logic that regulate intracellular compounds and cell numbers. But finally, in Part III, he sets out to take the reader on field expeditions to confirm that the ecological rules are analogous to the molecular rules of regulation. However, this all happens at a different level with limited opportunities for controlled experimentation. As Carroll put it on the first page, 'The anticipation in our Land Cruiser rises', and so it is for the reader. As a zoologist, I enjoyed Chapter 6, titled 'Some animals are more equal than others'. Carroll tells the story of Robert Paine, his life as a biology student and his interaction with the ecologist Fred Smith. Paine realised that to understand nature, one needs to understand the regulation of numbers, and to do this, he needed situations in which he could break the rules (intervene) and conduct so-called 'kick it and see' ecology experiments. He found such an opportunity at Mukkaw Bay, on the Pacific coast, where he removed starfish (predators) and tossed them into the ocean - according to Carroll, 'one of the most important experiments in the history of ecology' - thereby inventing the concept of a 'keystone species'. Carroll discusses more case studies - from otters controlling sea urchins (the latter controlling kelp) to fish-herbivorealgae cascades - to establish another concept, trophic cascades, characterised by a top-down control system but with the same principle of a double negative logic described by Monod and Jacob. As Carroll remarks: 'What began as tossing of starfish, has led to two fundamental insights' (the first two Serengeti rules). Firstly, keystones exert significant effects on the stability and diversity of their communities (hence not all species are equal); secondly, some members of food chains have strong (top-down) indirect effects on lower trophic levels. In Chapter 7 , Carroll takes us back into the Serengeti to introduce Tony Sinclair, an Oxford scholar who decided to spend his life in the Serengeti, starting with the understanding of the rules of regulation in an exponentially increasing buffalo population in the 1960s and 1970s. Carroll tells the story of the rinderpest virus and the control of buffalo and wildebeest, showing that a pathogen could also have a keystone role. The control of the virus unleashed amazing changes waiting for Sinclair to discover, such as the outbreak of trees and an increase in giraffe numbers. Carroll yet again connects the dots and draws attention to multiple levels of negative regulation, indeed triple negative logic, while conservationists initially blamed elephants for the loss of trees in the Serengeti! The role of wildebeest as competitors for resources becomes evident when following the numbers of grasshoppers, gazelles and others. Carrol now asks: What controls wildebeest in the absence of rinderpest? Could it be the body size predation issue or poaching? And what controls the larger species if predation does not? Density-dependent regulation or negative feedback as in molecular regulation? But then Sinclair observes mass deaths of wildebeest during a severe drought of 1993. There are thus two major ways of numbers control: predation and availability of food. But, Carroll asks, is there a way for larger antelope, like wildebeest, to circumvent these limiting factors? Migration? Carroll summarises Sinclair's Serengeti story by stating that our knowledge about regulation explains and answers so many 'Why' questions, but more importantly that the general rules of regulation turn out to be remarkably similar. Understanding these rules of regulation allows us to diagnose where they are broken and hopefully take the effort to cure them.

In Chapter 8, titled 'Another kind of cancer', Carroll introduces the reader to well-selected ecosystem examples in which 'regulatory rules' were broken (ecological cancers). Relevant here in South Africa, there is a discussion on the blooms of so-called blue-green algae, Microcystis (correctly known as cyanobacteria), known to produce lethal toxins (microcystin) in water associated with pollutants like phosphate compounds and glyphosate herbicides. Through several more examples (insect plagues, baboon and cownose ray population explosions), Carroll shows that common to all, just like tumour suppressors, understanding the rules of regulation is key to healing. Carroll also adds several more ecological cancers, such as brown planthopper insects plaguing the rice fields in Cambodia, explosions of olive baboon populations in Ghana and cownose rays in the USA. The common denominator among these three, very different, ecological cancers, is a decrease in natural predators (spiders, lions and sharks), just like tumour suppressors that act as proliferation brakes. Carroll recalls a comment by Sinclair that all problems of wildlife populations can be grouped into three categories: 'too many, too few and too much'. In the next chapter, Carroll presents a selection of examples of well-thought-out bio-manipulations. Striking is the story of the wolves of Yellowstone National Park. This brings us to one of the most ambitious restoration projects in Africa - that of the Gorongosa National Park in central Mozambique. In this instance, scientists had to deal with the communities surrounding the park and with poaching - humans as the top predator.

In the Afterword, Carroll tells one last story of the smallpox virus and the man who took the trouble to save the 'house on fire' - very similar to the 'rinderpest story', another example of how humans can control biology when human health is at stake.

This book by Sean Carroll is a life changer! A must read for anyone vaguely interested in science history to appreciate how miracles in science discovery happen and to understand the universality of biological regulation - 'Serengeti rules' that could be applied in therapy on a global scale. 